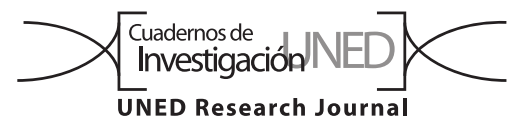

\title{
Actividad antimicrobiana del aceite de naranja residual
}

\author{
Dolores Castañeda-Antonio', Antonio Rivera-Tapia', Esther Choy-Flores², Ricardo Munguía-Pérez', \\ Roberto Portillo-Reyes ${ }^{3} \&$ Jesús Muñoz ${ }^{1}$
}

1. Centro de Investigaciones en Ciencias Microbiológicas, Instituto de Ciencias de la Benemérita Universidad Autónoma de Puebla; dcastaneda. antonio@gmail.com, jart70@yahoo.com, lewimx@yahoo.com.mx, joymerre@yahoo.com.mx

2. Facultad de Ingeniería Química de la Benemérita Universidad Autónoma de Puebla; estherchoy@live.com.mx

3. Facultad de Ciencias Químicas. Benemérita Universidad Autónoma de Puebla, roberto.portillo@correo.buap.mx

Recibido 09-IV-2018 • Corregido 09-VII-2018 • Aceptado 14-VIII-2018

\begin{abstract}
Antimicrobial activity evaluation of residual orange oil. The residue of the orange peel is a common contaminant in Mexico, even though it can be used in the cosmetic, pharmaceutical and food areas. We extract orange oil from residual skin, and determine its chemical compounds and antimicrobial activity. We used Soxhlet distillation, liquid-liquid extraction and pressing extraction, and gas chromatography coupled to mass spectrometry (GC-MS). We used a modified Kirby \& Bauer technique on Acremonium sp., Alternaria sp., Aspergillus niger, Candida albicans, Pseudomonas aeruginosa ATCC27853, Staphylococcus aureus ATCC 25923, Trichoderma sp. and Verticillium sp. The Soxhlet method was the most efficient (2,065\%). We observed inhibition values of $75 \%$ to $100 \%$ for S. aureus and P. auroginosa; 75 to $100 \%$ for Candida albicans; and 50 to $74 \%$ for Pseudomonas auroginosa. It acted as fungistatic for all strains. The CG-MS profile was: D-limonene $85,93 \%$, $\beta$-myrcene 2,23\%, linalool 1,72\%, decanal 0,63\%, a-pinene $0,43 \%$ and sabinene $0,20 \%$ per $\mu \mathrm{L}$ of oil per Head-space and per direct injection (main components: alkanes, and perilic alcohol, D-limonene and linalool).
\end{abstract}

Key words: Inhibition, microorganisms, oil, orange, waste.
RESUMEN: El residuo de la cáscara de naranja es un contaminante común en México, a pesar de que puede usarse en las áreas cosmética, farmacéutica y alimenticia. Extrajimos el aceite de naranja a partir de cáscara residual y determinamos sus compuestos químicos y su actividad antimicrobiana. Utilizamos la destilación Soxhlet, extracción líquido-líquido y extracción de prensado, y cromatografía de gases acoplada a espectrometría de masas (GC-MS). Usamos una técnica de Kirby \& Bauer modificada en Acremonium sp., Alternaria sp., Aspergillus niger, Candida albicans, Pseudomonas aeruginosa ATCC27853, Staphylococcus aureus ATCC 25923, Trichoderma sp. y Verticillium sp. El método Soxhlet fue el más eficiente (2,065\%). Observamos valores de inhibición de 75\% a $100 \%$ para S. aureus y P. auroginosa; 75 a $100 \%$ para Candida albicans; y 50 a $74 \%$ para Pseudomonas auroginosa. Actuó como fungistático para todas las cepas. El perfil CG-MS fue: D-limoneno $85,93 \%, \beta$-mirceno $2,23 \%$, linalool $1,72 \%$, decanal $0,63 \%$, a-pineno $0,43 \%$ y sabineno $0,20 \%$ por $\mu \mathrm{L}$ de aceite por espacio de cabeza (Head-space) y por inyección directa (principales componentes: alcanos y alcohol perílico, D-limoneno y linalool).

Palabras clave: Inhibición, microorganismos, aceite, naranja, desechos.
La naranja genera residuos poco usados en composta debido a que acidifican el medio. En las zonas rurales se usa para alimentar a los animales de corral, pero en las ciudades incrementa la cantidad de desechos orgánicos que tienen como destino final el basurero municipal. Sin tratamiento previo puede ocasionar problemas en los mantos freáticos debido a los lixiviados, entre otros. Otro uso importante es la obtención de aceite de naranja el cual presenta múltiples aplicaciones en la industria química, alimenticia, farmacéutica, perfumería y agronómica (Yañez, Lugo \& Parada, 2007; Hernández-Carillo, Valdez-Fragoso, Welti-Chanes \& Mujica-Paz, 2015).
En el 2017 México alcanzó el quinto lugar en producción de naranja a nivel mundial, con 4,2 millones de toneladas, la ciudad de Puebla, aporta junto con Nuevo León, Yucatán, Sonora, Tabasco, Hidalgo y Oaxaca, el 69,7\% de esta producción (Tecnología ambiental, 2018).

El presente trabajo se enfocó en la extracción del aceite de naranja a partir de la cáscara generada por comercios informales en la ciudad de Puebla y proponer una aplicación a este aceite como un producto inhibitorio de microorganismos. Los resultados de esta investigación serán la base para futuras investigaciones 
relacionadas con el aprovechamiento y tratamiento de este residuo orgánico.

\section{MATERIALES Y MÉTODOS}

Se realizó muestreo durante los meses de junio a agosto del 2015, dónde es mayor el consumo de naranja, se obtuvo el residuo orgánico (cáscara de naranja) producido por comercios ambulantes ubicados en las inmediaciones de Ciudad Universitaria (Puebla, México). Este desecho se procesó limpiando la cáscara de naranja, quitándole el bagazo, reduciéndose el tamaño de partícula para aumentar el área de contacto. Posteriormente se utilizó $1 \mathrm{~kg}$ para cada método de extracción de aceite y $90 \mathrm{~g}$ para determinar el porcentaje de humedad. Como referencia de aceite recuperado se usó cáscara de naranja sin exprimir, para un comparativo con la cáscara de los comercios, que ha sufrido una compresión previa. Se pesaron cantidades iguales de esta cáscara control para los métodos de extracción de aceite.

Se emplearon tres métodos de extracción de aceite: destilación con equipo Soxhlet, extracción líquido-líquido y extracción por prensado; cada extracción se hizo por triplicado.

Para la destilación con equipo Soxhlet se maceró la cáscara de naranja con hexano por un periodo de 7 días en un área obscura. Posteriormente se destiló con el equipo Soxhlet, se concentró en rota vapor y se limpió por filtración con florisil y sulfato de sodio anhidro, se eliminó solvente a $25^{\circ} \mathrm{C}$ en estufa de secado.

Para la extracción de aceite líquido-líquido, la cáscara de naranja se maceró en las mismas condiciones que el método anterior. Se filtró y se vertió en un embudo de separación donde se le adicionó $10 \mathrm{~mL}$ de hexano y 5 gotas de ácido sulfúrico concentrado. Se agitó vigorosamente durante 5 minutos y se dejó reposar de 10 a 15 minutos. Cuando se separaron las fases, la fase orgánica recuperada se vertió en tubos falcón y se centrifugaron a 5000 rpm durante 10 minutos a $5^{\circ} \mathrm{C}$, se concentró con "rota vapor". Para asegurar que el aceite no contuviera residuos del solvente se metió a la estufa a $25^{\circ} \mathrm{C}$ durante 24 horas.

En la extracción por prensado, la cáscara previamente limpia y cortada, se colocó dentro de una plantilla plástica que se colocó en un tornillo de banco de 2.5 pulgadas (utilizado como prensa). El producto obtenido se centrifugó a $5000 \mathrm{rpm}$ durante 10 minutos a $10^{\circ} \mathrm{C}$. Todos los aceites obtenidos se esterilizaron por filtración.
Para verificar la eficiencia de cada método de extracción se calculó el porcentaje de rendimiento (\%R) propuesto por Juárez et al., 2010 mediante la siguiente fórmula:

$$
\frac{V_{A O}}{P} \times 100=\% R
$$

Donde,

$\%$ R: Porcentaje de rendimiento

$\mathrm{V}_{\mathrm{AO}}$ : Volumen de aceite obtenido $(\mathrm{mL})$

$\mathrm{P}$ : Peso de la muestra a destilar (g)

Se determinó el porcentaje de humedad contenida en la cáscara para conocer su peso seco y se determinó con ello la eficiencia de recuperación del aceite. En este procedimiento se hizo por triplicado, se colocaron en las cápsulas (previamente a peso constante) $30 \mathrm{~g}$ de cáscara y se secaron a $105^{\circ} \mathrm{C}$ durante 24 horas, transcurrido este tiempo se metió al desecador para que se enfriaran las cápsulas y posteriormente se pesaron. Esta determinación se llevó a cabo de acuerdo al método empleado por Ramírez y Mendoza (2008) en donde el porcentaje de humedad se determinó con la siguiente fórmula:

$$
\frac{A}{B} \times 100=\% \text { Humedad } \quad \text { Ecuación (2) }
$$

Donde,

A: Diferencia de peso perdido

B: Peso inicial de la muestra

El cálculo necesario para determinación de peso seco $\left(\% \mathrm{P}_{\text {seco }}\right)$ de la cáscara se realizó con la siguiente fórmula, propuesta por Ramírez y Mendoza (2008)

$$
\frac{\left(P_{f N}+P_{c}\right)-P_{c}}{P_{i N}} \times 100=\% P_{\text {seco }} \quad \text { Ecuación (3) }
$$

Donde,

$\mathrm{P}_{\mathrm{fN}}$ : Peso final de la cáscara de naranja

$P_{\text {in: }}$ Peso inicial de la cáscara de naranja

$P_{c}:$ Peso de la cápsula

Posteriormente se determinaron los componentes del aceite por cromatografía de gases, con el objetivo de conocer los compuestos que le confieren sus propiedades 
inhibitorias de microorganismos. Se utilizó un cromatógrafo de gases series GC Agilent Technologies HP 7890 acoplado a un detector selectivo de masas 5973 Network Agilent, con columna capilar $30 \mathrm{~m}$ x $25 \mu \mathrm{m}$ x $0,25 \mathrm{~mm}$ marca HP, con inyector split/splitless. El modo de inyección de la muestra para determinar compuestos orgánicos volátiles y semivolátiles fue por espacio de cabeza (Head-space) y la identificación de componentes no volátiles se realizó por inyección directa. Estabilizado el equipo, se cargó el programa de aceite con las condiciones de Inyector: temperatura: $200^{\circ} \mathrm{C}$; presión: $17 \mathrm{psi}$; flujo: $42,3 \mathrm{~mL} / \mathrm{min}$; relación 40:1. Columna: DB-5MS, $0,25 \mathrm{~mm} \times 30 \mathrm{~m} \times 0,25 \mu \mathrm{m}$; temperatura máxima: $350^{\circ} \mathrm{C}$; presión a vacío: $17 \mathrm{psi}$. Horno: temperatura inicial: $50^{\circ} \mathrm{C}$ por minuto; temperatura final: $250^{\circ} \mathrm{C}$ por 25 minutos. Detector: temperatura: $250^{\circ} \mathrm{C}$.

Se evaluó la capacidad inhibitoria de microorganismos de cada aceite extraído, para ello los hongos se obtuvieron de una muestra de uña afectada por onicomicosis, que se sembró en tubo con agar papa dextrosa (PDA) para posteriormente aislar cada uno de los hongos obtenidos. Se sembraron en agar Borelli con antibiótico (Cefuroxima, $19,6 \mathrm{mg} / \mathrm{l}$ ) a una temperatura de $25^{\circ} \mathrm{C} \pm 2^{\circ} \mathrm{C}$. Las bacterias se tomaron de cepas ATCC y se sembraron en agar cuenta estándar (ACS) a $37^{\circ} \mathrm{C} \pm 2^{\circ} \mathrm{C}$. Tanto para hongos y bacterias, estos cultivos se hicieron por triplicado, sembrando cada cepa por extensión en placa. Los extractos obtenidos se sometieron a prueba aplicando el aceite en forma directa sin dilución con los ocho microorganismos diferentes: Acremonium sp., Alternaria sp., Aspergillus niger, Candida albicans, Pseudomonas aeruginosa ATCC27853, Staphylococcus aureus ATCC 25923, Trichoderma sp y Verticillium sp.

La técnica de difusión en placa se modificó, sustituyendo los sensidiscos por la aplicación directa de $10 \mu \mathrm{L}$ de cada uno de los extractos y como control se usó un aceite de naranja comercial. El monitoreo de cada placa se realizó a las 24 y 48 horas para las bacterias y en el caso de los hongos dermatofitos hasta 5 días. La actividad antimicrobiana se determinó midiendo el diámetro del halo de inhibición tomando como referencias los valores indicados por García Martos, Fernández del Barrio y Paredes Salido (1997).

Los datos obtenidos se sometieron a análisis de varianza (ANOVA) y su respectiva comparación múltiple de Tukey, el nivel de significación se estableció en $p<0,05$ utilizando el paquete estadístico OriginPro Versión 8.0

\section{RESULTADOS}

El método de extracción de aceite más eficiente de los analizados en este estudio fue la extracción con equipo Soxhlet ya que se obtuvo mayor cantidad de aceite de naranja $(19 \pm 2 \mathrm{~mL})$, siendo la extracción por prensado y líquido-líquido los menos eficientes $(0,85 \pm 0,15 \mathrm{~mL}$, $0,06 \pm 0,04 \mathrm{~mL}$, respectivamente). Los porcentajes promedio del rendimiento obtenidos fueron de $2,065 \%$ para la destilación Soxhlet, 0,09\% para el prensado y 0,006\% para la extracción líquido-líquido.

La determinación de humedad dio como resultado que la cáscara de naranja contiene $8,55 \%$ de humedad lo cual indica que el $91,45 \%$ es peso seco.

En relación a los resultados presentados podemos proponer a la cáscara residuo de los comercios de jugos para obtener aceite, ya que su rendimiento en comparación a la cáscara control no varía significativamente (Fig. 1). La destilación con equipo Soxhlet fue el método más efectivo de recuperación de cantidad de aceite y componentes volátiles recuperados, y la extracción por prensado presentó la ventaja de ser más económica que la mencionada anteriormente.

El análisis cromatográfico mostró el siguiente cromatograma (Fig. 2), en el cual los picos que destacan son los correspondientes al D-limoneno, $\beta$-mirceno, linalool, decanal, a-pineno y sabineno, concentraciones similares a lo reportado por Chaimala y Phutdhawong (2007),

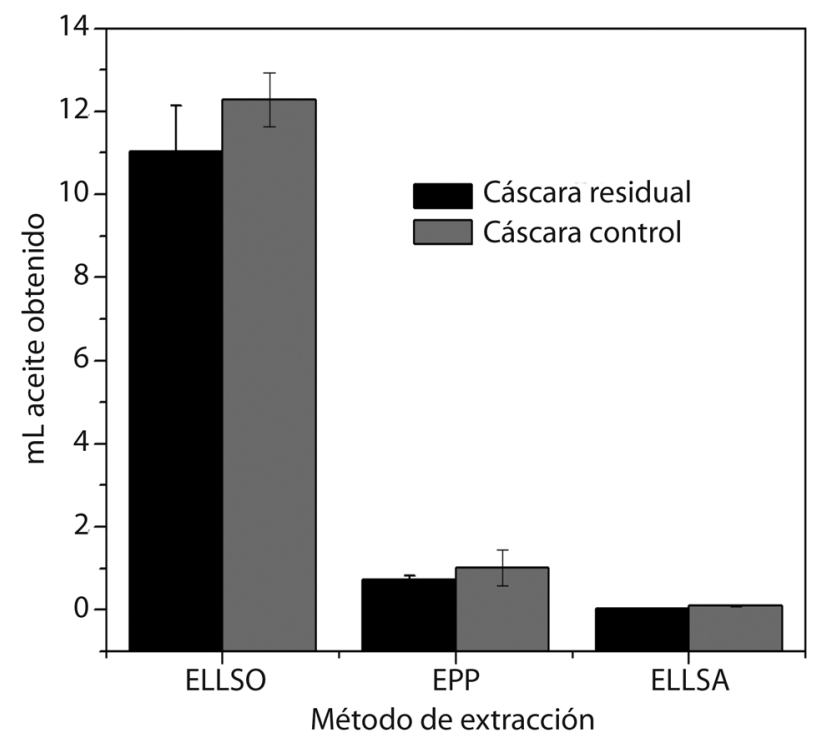

Fig. 1. Resultados de obtención de aceite de naranja. ELLSO (extracción líquido-líquido con solvente orgánico). EPP (extracción por prensado). ELLSA (extracción líquido-líquido con solvente acuoso). 


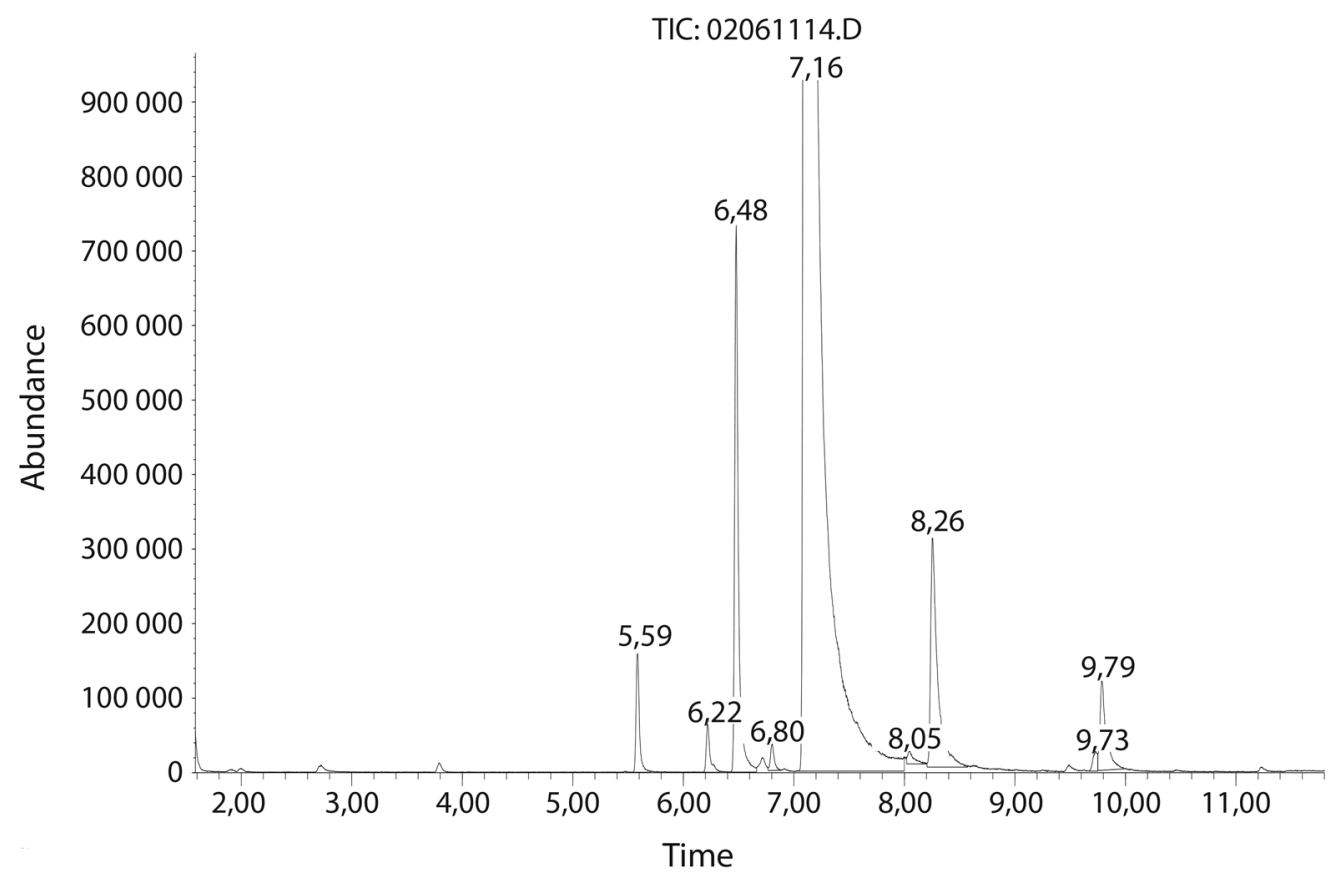

Fig. 2. Cromatograma de aceite de naranja (Head-space).

Juárez et al. (2010), en el Cuadro 1 se muestran los tiempos de retención y el porcentaje de cada compuesto presente en el aceite.

CUADRO 1

Compuestos detectados por CG-EM técnica por Head-space

\begin{tabular}{ccc} 
Tiempo de retención (min) & Compuesto & Porcentaje \\
7,16 & D-Limoneno & 85,93 \\
6,48 & $\beta$-Mirceno & 2,23 \\
5,59 & a-Pineno & 0,43 \\
8,26 & Linalool & 1,72 \\
9,79 & Decanal & 0,63 \\
- & Otros & 0,92 \\
\hline
\end{tabular}

Por inyección directa se encontró en mayor cantidad de alcanos (Fig. 3), y destacándose que entre los compuestos detectados en el análisis resaltan el D-limoneno en el minuto 12,19 y linalool al minuto 13,18 , otro compuesto de presencia notable fue el alcohol perílico al minuto 6,45 , importantes por sus propiedades medicinales (Chao et al., 2017; Juárez et al., 2010).

En el Cuadro 2 se presentan los compuestos detectados por CG-EM inyección directa y por Headspace, describiendo las aplicaciones reportadas en dichos compuestos.

Para la inhibición se compararon cada uno de los extractos obtenidos de los dos tipos de cáscara (control y residuo) y un aceite comercial. Para leer los halos de

CUADRO 2

Comparación de los compuestos detectados por Head-space e inyección directa y sus aplicaciones

\begin{tabular}{|c|c|c|c|c|}
\hline Compuestos & $\begin{array}{l}\text { Head-space } \\
\text { (\%) }\end{array}$ & $\begin{array}{l}\text { Inyección } \\
\text { directa (\%) }\end{array}$ & Aplicaciones & Referencia \\
\hline D-Limoneno & 85,93 & 8,76 & $\begin{array}{l}\text { Propiedades quimiopreventivas y quimioterapéuticas de } \\
\text { cáncer de mama, piel, pulmón y estómago }\end{array}$ & Chao et al. (2017) \\
\hline$\beta$-Mirceno & 2,23 & 0,0 & Propiedades antimicrobianas & Torres-Álvarez et al. (2017) \\
\hline a-Pineno & 0,43 & 0,0 & Propiedades antimicrobianas & Torres-Álvarez et al. (2017) \\
\hline Linalool & 1,72 & 0,17 & En la industria cosmética por propiedades odoríficas & Li et al. (2017) \\
\hline Decanal & 0,63 & 0,0 & Para dilución de productos cosméticos & Mettler (2006) \\
\hline
\end{tabular}




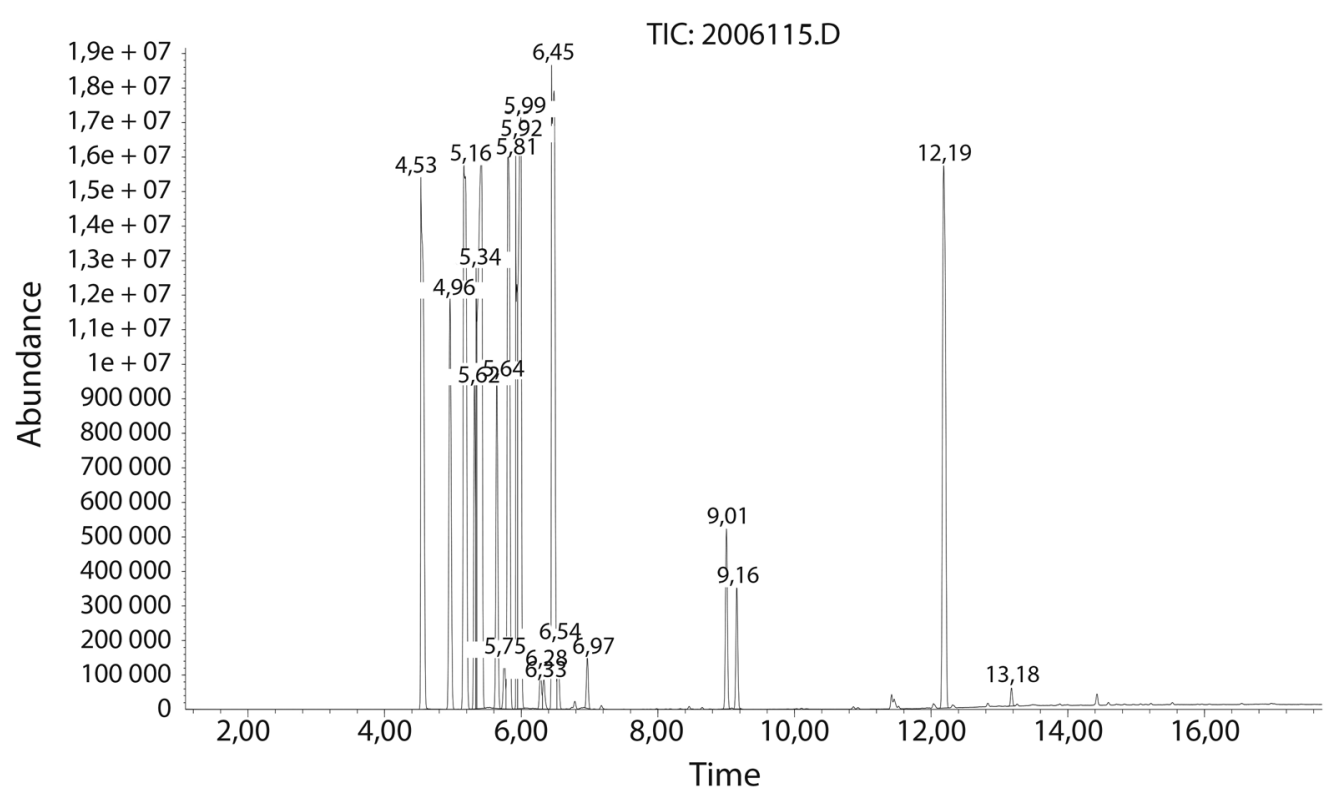

Fig. 3. Cromatograma de aceite de naranja inyección directa.

inhibición y establecer los parámetros en el presente trabajo teniendo halos de inhibición moderada de 50-74\% la sensibilidad intermedia e inhibición alta de 75-100\% como la respuesta sensible.

Respecto a la actividad microbiana de los extractos de la cáscara residuo se presentó inhibición moderada para Staphylococcus aureus y Candida albicans, presentando una sensibilidad intermedia al extracto obtenido por destilación con equipo Soxhlet. Staphylococcus aureus también presentó sensibilidad intermedia con el extracto por líquido-líquido. Mientras que los demás microorganismos mostraron resistencia a todos los aceites utilizados.

\section{DISCUSIÓN}

El porcentaje de rendimiento del método de destilación con equipo Soxhlet utilizando como solvente hexano coincide con lo reportado por Cardona, Ríos y Restrepo (2006), y las deficiencias en el método de extracción por prensado se deben a que, al comprimir la cáscara, una cantidad del aceite queda adherido a la plantilla plástica utilizada al igual que en el frasco contenedor, previo a la centrifugación. El bajo rendimiento en la extracción líquido-líquido con solvente acuoso se le atribuye al proceso de fermentación que se lleva a cabo en la maceración y a las pérdidas causadas por el restante adherido a las paredes del embudo de separación. Se encontró que la cáscara control presenta mayor rendimiento que la cáscara residuo, sin embargo, no se obtuvo variación en la obtención del aceite de la cáscara residual.

El porcentaje de humedad reportado por Tejeda et al. (2010) en cáscara de naranja es de 69,39\%, no coincidiendo con el valor obtenido en el presente trabajo. Siendo relevante destacar las múltiples aplicaciones que puede tener no solo el aceite de la cáscara residual de la naranja, ya que también se han reportado trabajos donde le dan una aplicación en el campo del uso medicinal, como compuestos bioactivos y recientemente su aplicación de la biomasa de la cáscara de naranja en la remoción de plomo en áreas contaminadas por este metal (Mahabir \& Guilliford, 1997; Rincón, Vásquez, Padilla \& Fanny, 2005; Tejeda, Herrera \& Nuñez, 2016).

El contenido de $D$-limoneno y $\beta$-mirceno indica que el aceite obtenido contiene estos compuestos presentes en aceite de naranja certificados. También se encontraron otros compuestos como el decanal y linalool coincidiendo con lo reportado por Juárez et al. (2010). De acuerdo a otro análisis realizado por Yáñez et al. (2007) y Yilmazoglu y Akgun (2018), se establece que el limoneno es el compuesto que resalta de los demás por las cantidades en la que se presenta. Los beneficios que se le atribuyen a los aceites de cítricos tiene que ver con sus componentes principales (D-limoneno y alcohol perílico) que les otorgan propiedades quimiopreventivas y quimioterapéuticas de cáncer de mama, piel, pulmón y estómago (Chao et al., 2017). Mientras que en otros compuestos como el linalool, $\beta$-mirceno, decanal y pineno (flavonoides, antraquinonas, curaminas, etc) reportan 
actividad biológica y le atribuyen al aceite propiedades antimicrobianas (Nannapaneni et al., 2009; Geraci, Stefano, Martino, Schillaci \& Schicchini, 2017).

Los resultados obtenidos por cromatografía, coinciden con lo reportado bibliográficamente, por lo que se establece que el aceite de naranja sí contiene compuestos con propiedades inhibitorias para Staphylococcus aureus y Candida albicans.

En conclusión, se puede aprovechar la cáscara residuo de los comercios de jugos para obtener aceite, debido a que su rendimiento presenta una diferencia no significativa en comparación con la cáscara control. El método de extracción con equipo Soxhlet fue el más efectivo para la obtención de la cantidad de aceite y componentes volátiles recuperados. Se sugiere la factibilidad del empleo del aceite obtenido a partir de cáscara residual como auxiliar a los tratamientos contra Staphylococcus aureus y Candida albicans, siempre y cuando su aplicación sea tópica, no se ingiera y se tenga la confirmación de cualquiera de estos agentes etiológicos.

\section{REFERENCIAS}

Cardona, E.M., Rios, L.A., \& Restrepo, G.M. (2006). Extracción del carotenoide licopeno del tomate chonto (Lycopersicum esculentum). Vitae, 13(2), 44-53.

Chao, Y., Hui, C., Hongli, C., Balian, Z., Xuzhong, L., \& Jiong, C. (2017). Antioxidant and anticancer acivities of essential oil from Ganna navel orange peel. Molecules, 22(8), 1391. doi: 10.3390/molecules22081391

Chaimala, P., \& Phutdhawong, W. (2007). Quality Certification. Organic Chemistry Research Unit. Tailandia: Maejo University.

García Martos, P., Fernández del Barrio, M. T., \& Paredes Salido, F. (1997). Microbiología Clínica Práctica. Madrid, España.

Geraci, A., Stefano, V. D., Martino, E. D., Schillaci, D., \& Schicchini, R. (2017). Essential oil components of orange peels and antimicrobial activity. Natural Product Research, 31(6), 653-659. doi: 10.1080/14786419.2016.1219860

Hernández-Carillo, J. G., Valdez-Fragoso, A., Welti-Chanes, J., \& Mujica-Paz, H. (2015). Tracing phenolic compounds through manufacturing of edible films from orange and grapefruit peels. Revista Mexicana de Ingeniería Química, 14(3), 567-578.

Juárez, J., Castro, A., Jauregui, J., Lizano, J., Carhuapona, M., Choquesillo, F., Felix, L., Cotillo, P., Lopez, J., Jaramillo, M., Cordova, A., Ruiz, J., \& Ramos, N. (2010). Composición química, actividad antibacteriana del aceite esencial de Citrus sinensis L. (Naranja dulce) y formulación de una forma farmacéutica. Ciencia e Investigación, 13(1), 9-13.
Li, Y., Liu, X., Jiang, J., Xia, J., Dang, L., Duan, Y., \& Zhe, W. (2017). Analysis of aroma components in orange oil by GC/ MS combined with the retention index. Journal of Food Sceince and Biotechnology, 36(4), 438-442.

Mahabir, D., \& Guilliford, M.C. (1997). Use of medicinal plants for diabetes in Trinidad and Tobago. Revista Panamericana de Salud Pública, 1(3), 174-179. doi: 10.1590/ S1020-49891997000300002

Mettler, T. (2006). Cosmética: pesada y análisis en el laboratorio. Cosmética News, 6, 6-8

Nannapaneni, R., Chalova, V., Story, R., Wiggins, K. C., Crandall, P. G., Ricke, S. C., \& Johnson, M. G. (2009). Ciprofloxacinsensitive and ciprofloxacin-resiatant Campylobacter jejuni are equally susceptible to natural orange oil-based antimicrobials. Journal of Environmental Science and Health, 44(6),571-577.doi:10.1080/03601230903000594

Rámirez, P., \& Mendoza, A. (2008). Ensayos toxicológicos para la evaluación de sustancias químicas en agua y suelo. La experiencia en México, Secretaria de Medio Ambiente y Recursos Naturales. Instituto Nacional de Ecología, México, D.F., México.

Rincón, A.M., Vásquez, A., Padilla, M., \& Fanny, C. (2005). Composición química y compuestos biactivos de las harinas de cascaras de naranja (Citrus sinensis), mandarina (Citrus reticulata) y toronja (Citrus paradisi) cultivadas en Venezuela. Archivos Latinoamericanos de Nutrición, 55(3), 305-310.

Tecnología ambiental. (2018). Producción de naranja en México, quinto lugar mundial. Recuperado de https://tecnologiaambiental.mx/2017/01/11/ produccion-de-naranja-mexico

Tejeda, P., Tejeda, C., Villabona, A., Alvear, M., Castillo, C., Heneao, D., Marimon, W., Madarigan, N., \& Taron, A. (2010). Producción de bioetanol a partir de la fermentación alcohólica de jarabes glucosados derivados de cáscaras de naranja y piña. Revista Educación en Ingeniería, 5(10), $120-125$.

Tejeda, T. C., Herrera, A., \& Nuñez, Z. J. (2016). Remoción de plomo por biomasas residuales de cáscara de naranja (Citrus sinensis) y zuro de maíz (Zea mays). Revista UDCA Actualidad y Divulgación Científica, 19(1), 169-178.

Torres-Álvarez, C., González, A. N., Rodríguez, J., Castillo, S., Leos-Rivas, C., \& Baez-González, J. G. (2017). Chemical composition, antimicrobial, and antioxidant activities of orange essential oil and its concentrated oils. Journal of Food, 15(1), 129-135.

Yañez, X., Lugo, L., \& Parada, D. (2007). Estudio del aceite esencial de la cáscara de la naranja dulce (Citrus sinesis, variedad valenciana) cultivada en Labateca, norte de Santander Colombia. Revista Bistua, 5(1), 3-8.

Yilmazoglu, E., \& Akgun, M. (2018). P-Cymene production from orange peel oil using some metal catalyst in supercritical alcohols. Journal of Supercritical Fluids, 13, 137-146. 